\title{
The effect of dietary polyunsaturated fat on cation transport and hypertension in the rat
}

\author{
BY GORDON E. MURRAY, RAMAN NAIR AND JOHN PATRICK* \\ Departments of Biochemistry and Pediatrics, University of Ottawa, Ottawa, \\ Canada K1H 8 M5
}

(Received 2 July 1986 - Accepted 16 July 1986)

\begin{abstract}
1. Essential hypertension is associated with increased intracellular sodium in both erythrocytes and leucocytes. Reports in the literature indicate that increasing the level of polyunsaturated fat in the diet reduces hypertension. In the present study, spontaneously hypertensive rats (Wistar-Kyoto, which develop systolic blood pressures in excess of $140 \mathrm{mmHg}$ by 8 weeks of age) were fed on high-fat diets ( $40 \%$ energy derived from fat), the fat being maize oil (high in polyunsaturated fatty acids, PUFA) and coconut oil (low in PUFA).

2. Significantly higher blood pressures developed by $110 \mathrm{~d}$ of age in the rats fed on a high-PUFA diet, compared with those fed on the low-PUFA diet.

3. In thymocytes, ouabain-sensitive efflux rate constants were significantly lower in the group fed on the high-PUFA diet. Ouabain-insensitive efflux rate constants were unaffected by diet.
\end{abstract}

The possibility of effective nutritional therapy for even a minor subset of the hypertensive population is of immense public-health significance, and also raises important questions about the hypertensive process. Extreme salt restriction was the earliest effective means of treatment but it had to be so severe that most patients opted for drug therapy as soon as it became available. This remains the case at present despite the current renewal of interest in low-salt regimens. There is also some evidence that dietary lipid may be an important modulator of blood pressure (Burstyn \& Firth, 1975; Burstyn \& Husbands, 1980; Düssing et al. 1983; Iacono et al. 1982, 1983; Puska et al. 1983). This finding is particularly interesting because of its potential interaction with current hypotheses relating abnormalities in membrane transport of sodium and calcium to the genesis and maintenance of hypertension (for review see Tosteson et al. 1981). As far as we know there have been no attempts to relate changes in blood pressure induced by alteration of dietary fat to associated changes in membrane transport and composition. In the present paper we report the effects of alteration in dietary polyunsaturated:saturated fat ratio (P:S) on blood pressure and thymocyte $\mathrm{Na}$ transport in one of the most extensively studied rat models of hypertension - the Wistar-Kyoto strain of spontaneously hypertensive rat.

\section{MATERIALS AND METHODS}

Wistar-Kyoto spontaneously hypertensive (SH) rats were obtained from the Charles River Breeding Laboratories, Wilmington, Mass., and placed on the experimental diets when 5 weeks old. They were housed in a room maintained at a temperature of $22^{\circ}$ with a $12 \mathrm{~h}$ light $-12 \mathrm{~h}$ dark cycle.

\section{Diet composition}

Fresh diet and water were available ad lib. Diets were prepared monthly and stored at $4^{\circ}$. They were based on those of Beare-Rogers et al. (1975), designed to be similar to the average Canadian intake of dietary fats, and had the following composition $(\mathrm{g} / \mathrm{kg})$ : casein 250 , sucrose 150 , maize starch 300 , alphacel 60 , fat 200 . The salt ( $30 \mathrm{~g} / \mathrm{kg}$ final diet) and vitamin

\footnotetext{
* For reprints.
} 
mix $(10 \mathrm{~g} / \mathrm{kg}$ final diet) were as described by Bernhart \& Tomarelli (1966), giving a final concentration (mg/kg diet) of: $\mathrm{Ca} 6000, \mathrm{P} 5000, \mathrm{Na} \mathrm{500,} \mathrm{K} \mathrm{1800,} \mathrm{Cl} \mathrm{500,} \mathrm{Mg} \mathrm{400,} \mathrm{Mn} \mathrm{50,}$ $\mathrm{Fe} 25, \mathrm{Zn} \mathrm{12,} \mathrm{Cu} \mathrm{5,} \mathrm{I} \mathrm{0 \cdot 15.} \mathrm{The} \mathrm{vitamin} \mathrm{mix} \mathrm{gave} \mathrm{a} \mathrm{final} \mathrm{concentration} \mathrm{(mg/g)} \mathrm{of:} \mathrm{thiamin}$ hydrochloride $6 \cdot 5$, riboflavin $12 \cdot 5$, pyridoxine hydrochloride 6 , niacin 75 , calcium pantothenate 40,2 -methylnaphthoquinone $0 \cdot 5$, biotin $0 \cdot 5$, folic acid $2 \cdot 0$, ascorbic acid 50 , $p$-aminobenzoic acid 100 , inositol 100 , DL- $\alpha$-tocopherol 120 , retinyl palmitate $1 \cdot 8$. Concentrations of vitamins $B_{12}$ and $D_{2}$ were 25 and $90 \mu \mathrm{g} / \mathrm{g}$ respectively. For the diet high in polyunsaturated fatty acids (PUFA), commercially available maize oil (Mazola ${ }^{\circledR}, 45 \%$ polyunsaturated) was used. For the low-PUFA diet, a mixture of coconut oil (ICN Nutritional Laboratories) and maize oil $(3: 1, \mathrm{w} / \mathrm{w})$ was used to avoid essential fatty acid deficiency which could result if coconut oil were the only fat source. At 5 weeks of age the animals were randomly assigned to a dietary group and fed on the diet for a minimum of 4 weeks before Na-transport measurements were made.

\section{Measurement of Na transport in thymocytes}

The medium used was 'Medium 199' (modified) with Earle's salts and glutamine (Flow Laboratories, Flow General, McLean, Virginia), the $\mathrm{pH}$ was adjusted to 7.35 with sodium bicarbonate which gave a final $\mathrm{Na}$ concentration of $140 \mathrm{mmol} / 1$, and a potassium concentration of $5.6 \mathrm{mmol} / \mathrm{l}$.

The procedure followed was that of Jones et al. (1981). The thymus glands from a group of rats were removed immediately following exsanguination and finely chopped into the medium. A cell suspension was prepared by gentle agitation followed by filtration through a fine gauze mesh. $\mathrm{Na}$ influx and efflux rate constants were measured in thymocyte cell suspensions which had been incubated at $37^{\circ}$ for at least $45 \mathrm{~min}$ and for no longer than 75 min. Ouabain-insensitive efflux was measured in the presence of 20 mm-ouabain octahydrate (strophanthin G; Sigma Chemical Co., St Louis, MO). Mason et al. (1985) have found that this is the optimal time for studies when cells have equilibrated with the media and show no evidence of diminished viability. $\mathrm{Na}$ influx ( $\mathrm{mmol} / \mathrm{kg}$ per $\mathrm{h}$ ) was calculated from the uptake of radioactivity by cells in $8 \mathrm{~min}$ when incubated in medium containing ${ }^{22} \mathrm{Na}$ at a measured specific activity. This value was then corrected for the efflux which had taken place during the influx measurement giving the 'corrected influx' according to the formula:

$$
\text { Corrected influx }=k \text { (observed influx }) /\left(1-\mathrm{e}^{-k t}\right)
$$

where $k$ is the efflux rate constant and $t$ the time in hours over which the influx was observed. The $\mathrm{Na}$ efflux rate constants were given by the slope of $\ln$ (radioactivity/dry weight) plotted against time (h) obtained from experiments in which thymocytes were loaded with ${ }^{22} \mathrm{Na}$, washed and the rate of loss of ${ }^{22} \mathrm{Na}$ measured.

\section{Measurement of intracellular $\mathrm{Na}$ and $\mathrm{K}$}

Portions of thymocytes were washed with isotonic magnesium chloride, freeze-dried, weighed and then wet-ashed in $1 \mathrm{M}$-nitric acid (Analar grade; Fisher). $\mathrm{Na}$ and $\mathrm{K}$ concentrations were measured by flame photometry (Model 443; Instrumentation Laboratory).

\section{Blood-pressure measurements}

The animals were warmed in an ambient temperature of $35^{\circ}$ for $15 \mathrm{~min}$, then systolic blood pressures were measured in the conscious, gently restrained animal using a tail cuff and electronic pulse detector. The mean of five readings over a $10 \mathrm{~min}$ interval was taken.

The animals were assigned at random to either the high- or low-PUFA diets. Because of the constraints on the number of animals which could be studied at one time, four series of experiments were run to compare the effect of the two diets on hypertension. It was found 
that the relation between age and blood pressure (BP) could be best described by the polynomial:

$$
\mathrm{BP}=I+l(\text { age })+q(\text { age })^{2}
$$

where $I$ is the intercept, $l$ the linear regression coefficient and $q$ the quadratic regression coefficient.

\section{Fatty acid composition of thymocytes}

Total lipids were extracted by the method of Bligh \& Dyer (1959), trans-esterified in 2.5\% methanolic hydrochloric acid and the resulting methyl esters analysed by gas-liquid chromatography on a column $(4 \mathrm{~mm} \times 2 \mathrm{~m})$ of SP- 2330 at $180^{\circ}$. Peaks were identified by comparison with methyl ester standards and peak area measured by the 'retention time $\times$ peak height' method of Carroll (1961).

\section{Statistical methods}

In the analysis of the effect of age on blood pressure for the two dietary groups, no significant serial correlation was observed among the residuals, thus a regression approach is valid. The data from the four series were pooled because regression analysis of the change in blood pressure with age revealed no significant variation between the experiments for either the high- or low-PUFA dietary groups.

In the measurement of $\mathrm{Na}$ efflux rate constants, results from experiments were discarded whenever the correlation coefficient for the plot of radioactivity/dry weight $v$. time was $<0.95(n 3)$.

\section{RESULTS}

Growth of animals

The animals were 5 weeks old when placed on the diets and their mean weight was $59 \cdot 1$ (SEM 2.3) $\mathrm{g}(n 40)$. Both groups gained weight at $2.6 \mathrm{~g} / \mathrm{d}$ and no differences in growth were observed between the two groups. No animals died during the study, nor was there any evidence of illness.

\section{Blood pressure}

As shown in Fig. 1, by $120 \mathrm{~d}$ of age the high-PUFA group developed a peak systolic blood pressure of $165 \mathrm{mmHg}$ followed by a slight decline up to $135 \mathrm{~d}$ when the experiment was terminated. The low-PUFA group on the other hand reached a maximum systolic pressure of $157 \mathrm{mmHg}$ at $105 \mathrm{~d}$ and their blood pressure fell markedly to $140 \mathrm{mmHg}$ by $133 \mathrm{~d}$. When the polynomial expression described above was fitted to these curves, both the linear and quadratic coefficients were significantly different from each other. The linear coefficient was 4.28 (SE 0.51) for high PUFA and 6.85 (SE 0.84) for low PUFA. The quadratic coefficients were - 0.017 (SE 0.002) for high PUFA and 0.032 (SE 0.004) for low PUFA. N was 153 (high PUFA) and 141 (low PUFA). These differences were significant $(P<0.05)$.

\section{Effect of diet on $\mathrm{Na}$ transport}

$\mathrm{Na}$ transport studies were performed on randomly selected animals between 60 and $110 \mathrm{~d}$ of age. There was no correlation between the age of the animal and any $\mathrm{Na}$ transport measurements. There was a significant decrease in ouabain-sensitive (the $\mathrm{Na}, \mathrm{K}$ ATPase-Na pump mediated) efflux rate constants in the high-PUFA compared with the low-PUFA groups. The ouabain-insensitive efflux rate constants were unaffected by diet (Table 1).

Table 2 shows the intracellular $\mathrm{Na}$ and corrected influx values. Neither measurement was significantly affected by diet. It should be noted that $n$ differs between groups because the yield of thymocytes varied; the priority of measurements was influx and intracellular electrolytes, then total efflux and finally ouabain-insensitive efflux. 


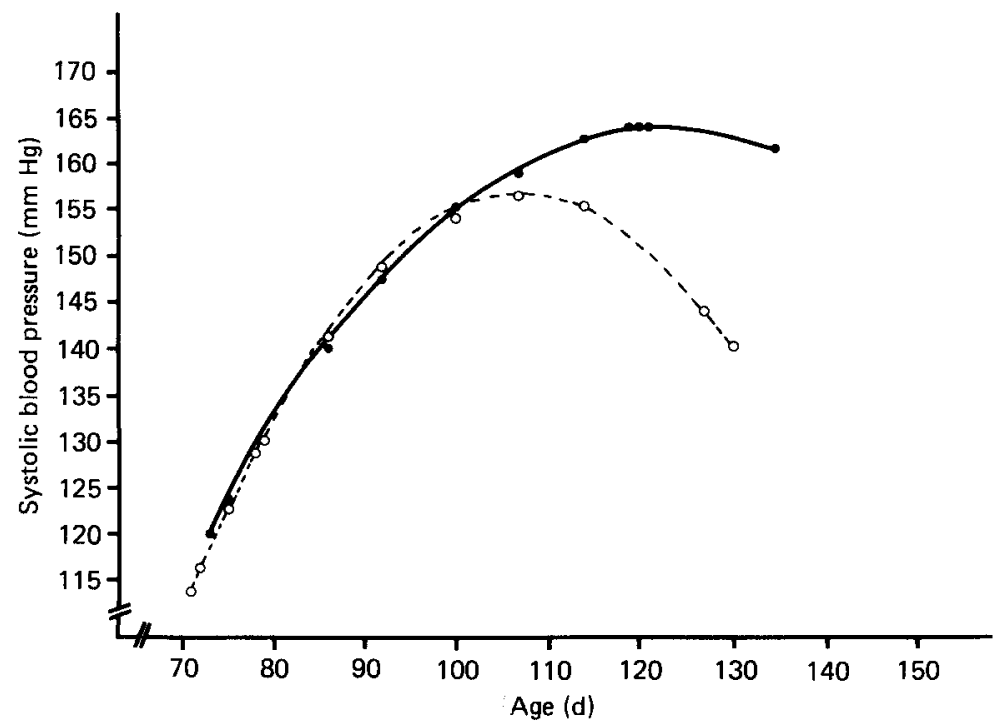

Fig. 1. Effect of high-fat diets ( $40 \%$ energy) with high and low levels of polyunsaturated fatty acids (PUFA) on the development of hypertension. (O), Maize oil (high PUFA); (O), coconut oil-maize oil ( $3: 1 \mathrm{w} / \mathrm{w}$; low PUFA). The blood pressure curves are described in terms of a polynomial expression in which both the linear and quadratic coefficients are significantly different $(P<0.05)$.

Table 1. Sodium efflux rate constants $(/ h)$ in spontaneously hypertensive rats fed on high-fat diets $(40 \%$ energy) with high and low levels of polyunsaturated fatty acids (PUFA)

(Mean values with their standard errors)

\begin{tabular}{|c|c|c|c|c|c|c|}
\hline \multirow[t]{2}{*}{ Diet... } & \multicolumn{3}{|c|}{ Low-PUFA } & \multicolumn{3}{|c|}{ High-PUFA } \\
\hline & Mean & SE & $n$ & Mean & SE & $n$ \\
\hline Total efflux rate constant $\dagger$ & $6 \cdot 5^{*}$ & $0 \cdot 33$ & 13 & $5 \cdot 4$ & $0 \cdot 33$ & 11 \\
\hline Ouabain-insensitive rate constant & $2 \cdot 4$ & $0 \cdot 15$ & 9 & $2 \cdot 5$ & $0 \cdot 33$ & 8 \\
\hline
\end{tabular}

* Mean value was significantly different from that for high-PUFA group (two-tailed $t$ test): $P<0.05$.

$\uparrow$ For details of method of measurement, see p. 588 .

Table 2. Corrected sodium influx and intracellular Na levels in spontaneously hypertensive rats fed on high-fat diets $(40 \%$ energy) with high and low levels of polyunsaturated fatty acids (PUFA)

(Mean values with their standard errors)

\begin{tabular}{|c|c|c|c|c|c|c|}
\hline \multirow[t]{2}{*}{ Diet... } & \multicolumn{3}{|c|}{ High-PUFA } & \multicolumn{3}{|c|}{ Low-PUFA } \\
\hline & Mean & $\mathrm{SE}$ & $n$ & Mean & $\mathrm{SE}$ & $n$ \\
\hline Intracellular $\mathrm{Na}$ (nmol/kg dry wt) & 50 & $2 \cdot 3$ & 13 & 50 & $4 \cdot 4$ & 16 \\
\hline Corrected influx (mmol $\mathrm{Na} / \mathrm{h}$ per kg dry wt)* & 270 & $12 \cdot 6$ & 13 & 281 & $16 \cdot 6$ & 16 \\
\hline
\end{tabular}

* Calculated from the measured influx and efflux rate-constants; see p. 588 . 
Table 3. Fatty acid composition ( $\mathrm{mmol} / \mathrm{mol}$ ) of thymocytes from spontaneously hypertensive rats fed on high-fat diets $(40 \%$ energy) with high and low levels of polyunsaturated fatty acids (PUFA)

(Total lipids were extracted by the method of Bligh \& Dyer (1959) and the fatty acids identified by gas-liquid chromatography (see p. 589). Values represent the average of triplicate measurements of total lipids from pooled thymus glands of five rats)

\begin{tabular}{cccccr}
\hline \hline Diet $\ldots$ & \multicolumn{2}{c}{ High-PUFA } & & \multicolumn{2}{c}{ Low-PUFA } \\
\cline { 2 - 3 } \cline { 5 - 6 } Age (d) $\ldots$ & 70 & 90 & & 70 & 90 \\
Fatty acid & & & & \\
\hline $12: 0$ & 12 & - & & 97 & 108 \\
$14: 0$ & 24 & 10 & & 87 & 90 \\
$16: 0$ & 220 & 186 & & 263 & 265 \\
$18: 0$ & 72 & 30 & & 72 & 52 \\
$18: 1$ & 235 & 184 & & 242 & 272 \\
$18: 2$ & 364 & 557 & & 136 & 162 \\
$20: 4$ & 35 & 26 & 39 & 5 \\
\hline \hline
\end{tabular}

Total lipid composition of thymocytes

At $90 \mathrm{~d}$ the major differences in fatty acid composition between the animals fed on highor low-PUFA diets were: higher 18:2 and 20:4 fatty acids on the high-PUFA diet, and higher 12:0,14:0, 16:0, 18:0 and 18:1 fatty acids on the low-PUFA diet (Table 3).

\section{DISCUSSION}

From this and other studies cited in the introduction it is apparent that blood pressure can be modulated by dietary fat. By $110 \mathrm{~d}$ the animals given the low-PUFA diet had lower systolic blood pressure than those given the high-PUFA diet, Box \& Mogenson (1982) reported similar results. After $110 \mathrm{~d}$, blood pressure declined in both groups. This result is qualitatively similar to that of Wexler (1981), but his findings were more dramatic. However, his diet, high in saturated fat, was deficient in essential fatty acids and consequently the rats did not grow normally. He also presented evidence that they had hypopituitarism. There was no evidence of growth failure in our animals. In contrast to human essential hypertension, and salt-induced experimental hypertension where a high $P: S$ ratio is hypotensive, a low $P: S$ in a high-fat diet is an effective hypotensive regimen in $\mathrm{SH}$ rats.

The mechanisms postulated to explain experiments with salt-dependent hypertension have centred on prostaglandin-mediated mechanisms (Dusting et al. 1981; Dickens et al. 1982; Düsing et al. 1983), particularly the possibility of low prostacyclin production from arachidonic acid (Puska et al. 1985). However, in our animals there was an increased amount of arachidonic acid in the membranes of the more hypertensive animals, making this an unlikely explanation. We were interested in the possibility that the mechanism might involve modulation of $\mathrm{Na}$ transport, either by direct modification of the physical characteristics of the cell membrane, or by an effect on circulating inhibitors of the $\mathrm{Na}$ pump. Innis \& Clandinin $(1981 a, b)$ have shown that dietary fat can directly modulate the physical properties of membranes and associated ATPase activity. Indeed, there is a considerable body of literature indicating such important effects and this has been reviewed by Wahle (1983). Hunt et al. (1986), in a study of Na-lithium counter-transport, Na-K co-transport and passive Li leak, found the passive Li leak to be most strongly correlated 
with blood pressure, suggesting a difference in cell membrane 'leakiness' as distinct from an alteration in active-transport systems. A similar change in the membranes of the animals fed on the high-PUFA diet would raise $\mathrm{Na}$ influx with consequent increase in efflux rate constants. Since we do not have a full fatty acid profile, it is not possible to correlate changes in the unsaturation index with the effect on Na-pump activity. However, the increased amount of arachidonic acid in the membranes of the animals fed on the high-PUFA diet would be expected to increase membrane fluidity, increasing $\mathrm{Na}$ influx and raising the rate constants for $\mathrm{Na}$ efflux, both ouabain-sensitive and ouabain-insensitive. This did not occur. We are led to the conclusion that PUFA may have more sophisticated effects on the $\mathrm{Na}$ pump, possibly affecting a lipid micro-domain (Klausner et al. 1980) which is spatially associated with the pump site or the $\mathrm{Na}$ channel or both.

The role of circulating-inhibitors in hypertension is currently very contentious. However, the animals with the highest blood pressure did have the lowest rate constants, agreeing with other work on the Na pump in leucocytes (Edmondson et al. 1975; Poston et al. 1981; Heagerty et al. 1982) and is in keeping with the idea that hypertension may be caused by circulating inhibitors of Na-pump activity (Hamlyn et al. 1982). The fact that influx and intracellular $\mathrm{Na}$ did not alter measurably is also a frequent phenomenon in the literature on $\mathrm{Na}$ transport in hypertension. Blaustein (1977) has calculated that the amount of change in intracellular $\mathrm{Na}$ required to modify intracellular $\mathrm{Ca}$ and hence resting tension, is well within the experimental error for group sizes such as ours. The only change we detected was in the rate constants for ouabain-sensitive $\mathrm{Na}$ efflux. While this is compatible with an alteration in the level of a circulating $\mathrm{Na}$ transport inhibitor, it seems more likely to result from a direct effect on the physical properties of the membrane, affecting a specific micro-domain (Klausner et al. 1980).

The authors wish to express their thanks to Elizabeth Sauer and Morris Kates for lipid analyses, and Robert Hanak for assistance with statistical analysis of the blood pressure data. This work was supported by a grant from the Medical Research Council of Canada.

\section{REFEREN CES}

Beare-Rogers, J. L., Gray, L., Nera, E. A. \& Levin, O. L. (1975). Nutrition and Metabolism 23, 335-346. Bernhart, F. W. \& Tomarelli, R. M. (1966). Journal of Nutrition 89, 495-500.

Blaustein, M. P. (1977). American Joumal of Physiology 232, C165-C173.

Bligh, E. C. \& Dyer, W. J. (1959). Canadian Joumal of Biochemistry and Physiology 37, 91 1-917.

Box, B. M. \& Mogenson, G. J. (1982). Nutrition Research 2, 619-627.

Burstyn, P. G. \& Firth, W. R. (1975). Cardiovascular Research 9, 807-810.

Burstyn, P. G. \& Husbands, D. R. (1980). Cardiovascular Research 14, 185-191.

Carroll, K. K. (1961). Nature 191, 377-378.

Dickens, P., Dusting, G. J., Doyle, A. E. \& Martin, T. J. (1982). Clinical and Experimental Pharmacology and Physiology 9, 253-257.

Düsing, R., Scherhag, R., Glanzer, K., Büdde, U. \& Kramer, H. (1983). American Journal of Physiology 244, $\mathrm{H} 228-\mathrm{H} 233$.

Dusting, G. J., Davies, W., Drysdale, T. \& Doyle, A. E. (1981). Clinical and Experimental Pharmacology and Physiology 8, 435-440.

Edmondson, R. P. S., Thomas, R. D., Hilton, P. J., Patrick, J. \& Jones, N. F. (1975). Lancet i, $1003-1005$.

Hamlyn, J. M., Ringel, R., Schaeffer, J., Levinson, P. D., Hamilton, B. P., Kowarski, A. A. \& Blaustein, M. P. (1982). Nature 300, 650-652.

Heagerty, A. M., Milner, M., Bing, R. F., Thurston, H. \& Swales, J. D. (1982). Lancet ii, 894-896.

Hunt, S. C., Williams, R. R., Smith, J. B., Ash, K. O. \& Kuida, H. (1986). Clinical and Experimental Hypertension A7, 1409-1426.

Iacono, J. M., Dougherty, R. M. \& Puska, P. (1982). Hypertension 4 (Suppl. III), 3442.

Iacono, J. M., Puska, P., Dougherty, R. M., Pietinen, P., Vartiainen, E., Leino, U., Mutanen, M. \& Moisio, S. (1983). American Journal of Clinical Nutrition 38, 860-869.

Innis, S. M. \& Clandinin, M. T. (1981a). Biochemical Journal 193, 155-167. 
Innis, S. M. \& Clandinin, M. T. (1981 b). Biochemical Journal 198, 167-175.

Jones, R. B., Patrick, J. \& Hilton, P. J. (1981). Clinical Science 61, 313-316.

Klausner, R. D., Kleinfeld, A. M., Hoover, A. M. \& Karnovsky, M. J. (1980). Journal of Biological Chemistry 255, 1286-1294.

Mason, J. C., Poston, L. \& Hilton, P. J. (1985). Clinical Science 68, 11-14.

Poston, L., Sewell, R. B., Wilkinson, S. P., Richardson, P. J., Williams, R., Clarkson, E. M., MacGregor, G. A. \& De Wardener, H. E. (1981). British Medical Journal 282, 847-849.

Puska, P., Nissinen, A., Vartiainen, E., Dougherty, R., Mutanen, M., Iacono, J. M., Korhonen, H. J., Pietinen, P., Leino, U. \& Moisio, S. (1983). Lancet $\mathbf{i}, 1-5$.

Puska, P., Nissinen, A., Pietinen, P. \& Iacono, J. (1985). Scandinavian Journal of Clinical and Laboratory Investigation 176 (Suppl.), 62-80.

Tosteson, D. C., Adragna, N., Bizet, I., Solomon, H. \& Canessa, M. (1981). Clinical Science 61 (Suppl. 7), 5s-10s.

Wahle, K. W. J. (1983). Proceedings of the Nutrition Society 42, 273-287.

Wexler, B. C. (1981). Endocrinology 108, 981-989. 